\title{
Suitability of Rapid Detection Methods for Salmonella in Poultry Slaughterhouses
}

\author{
J. M. Eijkelkamp • H. J. M. Aarts • \\ H. J. van der Fels-Klerx
}

Received: 11 April 2008 /Accepted: 23 June 2008 / Published online: 25 July 2008

(C) The Author(s) 2008

\begin{abstract}
In the perspective of an announced prohibition to bring Salmonella-contaminated fresh poultry meat on the retail market as of December 2010, requirements are postulated for rapid methods for detection of Salmonella in poultry meat. These rapid methods should deliver reliable results in time to make it possible to steer the finished products in poultry slaughterhouses into the direction of the fresh poultry market or into the direction of industrial treatment. The most important requirements are the detection limit ( $1 \mathrm{cfu} / 25 \mathrm{~g}$ ), the time of analysis (within hours up to a maximum of $24 \mathrm{~h}$ ), the sensitivity and specificity, and the validation of the rapid detection method. To determine a requirement for the number of samples to be analyzed per unit of time of the detection methods, a sampling plan for pooling of samples is suggested. Information of commercially available detection methods from literature and data provided by the suppliers was compared to the postulated requirements. The results showed that none of the commercially available detection methods meet all the suggested requirements. For all available methods, the time of analysis is too long to steer the production process in time. This implicates that faster methods should be developed before the announced prohibition can be sensibly introduced. Also, information about sensitivity and specificity, which is essential for the reliability of the rapid test method, should be examined in a more uniform way.
\end{abstract}

Keywords Salmonella $\cdot$ Rapid Methods · Food Safety · Chicken · Pathogens

J. M. Eijkelkamp • H. J. M. Aarts · H. J. van der Fels-Klerx ( $\square)$ RIKILT-Institute of Food Safety,

Wageningen UR, P.O. Box 230, NL-6700 AE Wageningen,

The Netherlands

e-mail: ine.vanderfels@wur.nl

\section{Introduction}

Salmonellosis is the second most frequently reported human zoonotic disease in the EU. For example, in 2005, an average incidence of 38.2 cases per 100,000 populations was reported. Salmonella was most frequently reported from poultry meat, followed by pig meat. The Member States reported positive findings in $0-18 \%$ of the tested samples of fresh broiler meat (Anonymous 2006a). In regulation (EC) 2160/2003 of the European Parliament and of the Council of 17 November 2003 on the control of Salmonella and other specified food-borne zoonotic agents (Anonymous 2003a), it is specified that, with effect from 84 months after entry into force of this regulation (December 2010), fresh poultry meat from broilers, laying hens, and turkeys may not be placed on the market for human consumption unless it meets the criterion: "Salmonella: absence in 25 grams." Detailed rules for this criterion, in particular with respect to sampling schemes and analytical methods, will be laid down 12 months before. The criterion does not apply to fresh poultry meat destined for industrial heat treatment or another treatment to eliminate Salmonella in accordance with community legislation on food hygiene. However, before a ban on contaminated poultry meat in the fresh retail market can be sensibly introduced, faster and more reliable detection methods for Salmonella should be developed. It is necessary to have the test results in time, enabling to steer the finished products in the desired direction, either fresh poultry for the retail market or industrial treatments to eliminate Salmonella. Although Regulation (EC) 2073/2005 (section 24) (Anonymous 2005a) stipulates that, due to the fact that test results are dependent on the analytical method used, a given reference method should be associated with each microbiological criterion. However, producers should have the possibility to 
use alternative (rapid) methods, as long as the use of these alternative methods provides equivalent results and the defined sampling plan enables a harmonized implementation. In case alternative rapid methods are used, food safety should be equivalently guaranteed. The detection methods currently applied are not suitable for the purpose to steer the finished products in the desired direction as it takes too long before the test results are available, and in addition, they deliver too many false-negative results (Tacken and van Horne 2006). The purpose of this paper is to propose requirements for rapid detection methods for Salmonella to be applied in poultry slaughterhouses, in order to prevent bringing Salmonella-contaminated meat on the market for human consumption, as well as to make an inventory of the extent to which current rapid methods fulfill these requirements.

First, the requirements with respect to rapid detection methods for Salmonella are put forward followed by an overview presenting the currently available rapid techniques for Salmonella detection. Furthermore, the most promising techniques are discussed in relation with the postulated requirements and, finally, a conclusion is drawn with respect to suitable methods. The information for this paper is acquired by means of literature study, websites of suppliers of rapid detection methods, and personal communications with representatives of these suppliers.

\section{Requirements for Rapid Methods for Detection of Salmonella}

There are several parameters which must be considered before adapting a new rapid detection method. These parameters can be divided into technical parameters such as detection limit, time of analysis, validation of the method, sensitivity and specificity, and additional parameters like equipment, operation, and costs (De Boer and Beumer 1999; Swanenburg et al. 2005; Meloen et al. 2001; Ivnitski et al. 2000; von Blankenfeld-Enkvist and Brännback 2002). In the case of a suitable method for detection of Salmonella in fresh poultry meat with the purpose to steer the destination of the finished products, the parameters of the method should fulfill the requirements, which are discussed below.

\section{Detection Limit}

The detection limit is the lowest concentration of an analyte in a sample that can be detected with a reasonable statistical certainty. According to the requirements laid down in regulation EC 2160/2003 (Anonymous 2003a), fresh poultry meat should meet the requirement: "Salmonella absence in 25 gram." Therefore, the test should detect all serotypes of Salmonella present on poultry meat and should be able to detect a single Salmonella bacterium in $25 \mathrm{~g}$ of fresh poultry meat.

\section{Time of Analysis}

The time of analysis is defined as the total time for sampling, sample preparation, and detection. Fresh poultry meat for human consumption is preferably dispatched on the day of production or the next day at the latest. Every delay in dispatch will shorten the shelf life of the product in retail stores and at the consumers. Therefore, some retailers require from their suppliers that, on delivery, the poultry meat should originate from flocks, which are slaughtered the day before. Waiting for test results in order to ship can have a tremendous negative impact on the processor's ability to conduct business profitably. However, not waiting and having a sample tested positive for pathogenic contamination can result in costly recalls, human pain and suffering, loss of reputation, and costs associated with litigation (Evers 2004). Therefore, the test results should be available preferably within a couple of hours with a maximum of $24 \mathrm{~h}$. Because of this requirement, the test should be carried out in a laboratory "on site" to avoid any delay as a result of transporting the samples to an external laboratory. Another approach to have test results in time could be using the test results of the manure of the birds in the poultry houses, which are known before transport to the slaughterhouse. These test results are nowadays used for logistic slaughtering, i.e., slaughtering the Salmonellanegative flocks at the start of the day and the Salmonellapositive flocks at the end of the day. With logistic slaughtering, the level of potential cross-contamination in the slaughterhouse can be reduced. However, this method does not guarantee Salmonella-free flocks at the end of the production line (Russell 2004/2005). Test results may be false-negative, and possible cross-contamination and contamination of the meat due to other causes than the incoming birds may occur. Therefore, the method is not reliable enough to steer the finished products in the direction desired.

\section{Validation}

The aim of validation is to demonstrate that a new method is fit for its intended use. According to NEN-EN-ISO 16040 - protocol for the validation of alternative methods, the validation of an alternative method should demonstrate that adequate confidence is provided that the results obtained by the alternative method are comparable to those obtained using the reference method (Anonymous 2003b). Validation studies for alternative rapid detection methods 
for Salmonella have been described in literature (Malorny et al. 2003; Löfstrom et al. 2008).

But most of the validation studies are usually coordinated by an independent validation body, which has developed rules for this process. There are several validation bodies, e.g., AOAC (Association of Official Analytical Chemists, USA), AFNOR (Association Française de Normalisation, France), NordVal (part of the Nordic Committee on Food Analysis, Norway), and MicroVal (European Validation and Certification Organisation, Europe). It is necessary that a rapid method for Salmonella detection has been validated against a standardized protocol to ensure that the rapid method performs according to the specified requirements.

Reliability of the Test Method

The reliability of a test method can be expressed in one or more of the following parameters: accuracy, sensitivity, specificity, positive predictive value, and negative predictive value. These parameters are closely related terms, as presented in Fig. 1.

Accuracy is defined as the probability of the correspondence between the results obtained with the test and the true presence or absence of the contaminant. It can be calculated with Eq. 1:

$$
\begin{aligned}
& \text { Accuracy }(\%)=\frac{\text { true positives and true negatives }}{\text { total number of flocks }} \times 100 \% \\
& =\frac{a+d}{a+b+c+d} \times 100 \% \text {. }
\end{aligned}
$$

Note: $a, b, c$, and $d$ correspond to $\mathrm{a}, \mathrm{b}, \mathrm{c}$, and $\mathrm{d}$ in Fig. 1.

Sensitivity is defined as the probability of a sample testing positive if a contamination was truly present. It can be calculated with Eq. 2:

Sensitivity $(\%)=\frac{\text { true positives }}{\text { true contaminated flocks }} \times 100 \%=\frac{a}{a+c} \times 100 \%$.

Specificity is defined as the probability of a test being negative if a contamination is truly absent. It can be calculated with Eq. 3:

$$
\begin{aligned}
\text { Specificity }(\%) & =\frac{\text { true negatives }}{\text { true uncontaminated flocks }} \times 100 \% \\
& =\frac{d}{b+d} \times 100 \% .
\end{aligned}
$$

A failure to detect the contamination when present (false-negative test result) will lower the sensitivity of a test. A positive test result in absence of the contamination (false-positive test result) will lower the specificity of a test.

Positive predictive value (PPV) (Gunnarsson and Lanke 2002) is defined as the probability of a sample being contaminated if the result of the test is positive. The PPV can be calculated with Eq. 4 :

$$
\begin{aligned}
\operatorname{PPV}(\%) & =\frac{\text { true positives }}{\text { total positive test results }} \times 100 \% \\
& =\frac{a}{a+b} \times 100 \% .
\end{aligned}
$$

Negative predictive value (NPV) (Gunnarsson and Lanke 2002) is defined as the probability of a sample being not contaminated if the result of the test is negative. The NPV can be calculated with Eq. 5:

$$
\begin{aligned}
\mathrm{NPV}(\%) & =\frac{\text { true negatives }}{\text { total negative test results }} \times 100 \% \\
& =\frac{d}{c+d} \times 100 \% .
\end{aligned}
$$

Predictive values (PPV, NPV) are important in evaluating the utility of a new detection method since these values are a function of the sensitivity and specificity of the test and the prevalence of contamination in the population (Peplow et al. 1999). In Table 1, some figures are presented to illustrate this relationship. When keeping sensitivity and specificity constant and lowering the prevalence, the PPV of a test is reduced and the NPV is increased. At a fixed prevalence, improving the sensitivity of a test will lead to a higher NPV, while improving the specificity will lead to a higher PPV.

Flocks tested positive are not allowed to be used for fresh poultry meat for human consumption, the flock should be destined for industrial treatment to eliminate Salmonella, which will mean a decrease in economic value. From a food safety perspective, the number of flocks wrongly used for human consumption should be as low as possible, which requires a high NPV and, therefore, a high sensitivity. From an economic point of view also, the number of flocks wrongly decreased in value should be as low as possible, which requires a high PPV and, therefore, a high specificity. For a given test, sensitivity and specificity are usually inversely related. Thus, if the test is altered to increase the sensitivity, then specificity decreases and vice

Fig. 1 Relationship between sensitivity, specificity, positive predictive value, and negative predictive value

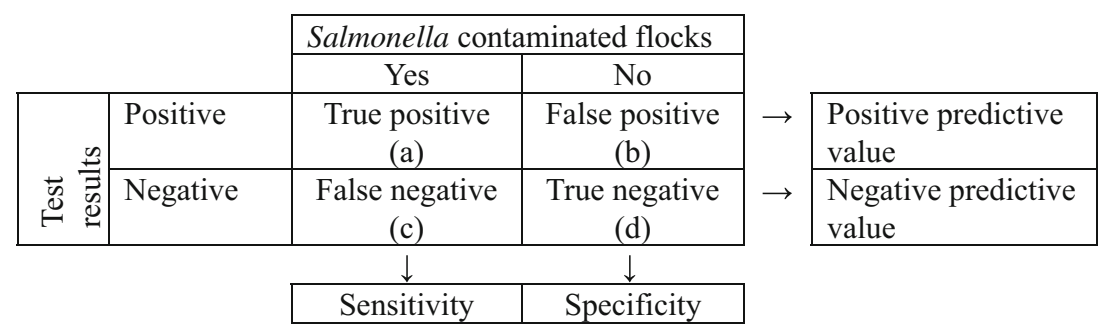


Table 1 Predictive values of a test as a function of sensitivity, specificity, and prevalence

\begin{tabular}{lcccc}
\hline Sensitivity (\%) & Specificity (\%) & Prevalence (\%) & PPV (\%) & NPV (\%) \\
\hline 95 & 95 & 30 & 89.1 & 98.8 \\
95 & 95 & 5 & 50.0 & 99.7 \\
95 & 95 & 1 & 16.1 & 99.9 \\
95 & 98 & 5 & 71.4 & 99.7 \\
98 & 95 & 5 & 50.8 & 99.9 \\
\hline
\end{tabular}

$P P V$ positive predictive value, $N P V$ negative predictive value

versa (Martin 1977). Therefore, it is important to agree on the level of sensitivity and specificity. Both should preferably be as high as possible. In NEN-EN-ISO 16140 (Anonymous 2003b), no requirements are specified with respect to sensitivity and specificity. Also, the validation bodies AOAC (Feldsine et al. 2002; Anonymous 1999) and MicroVal (Anonymous 2006b) do not specify acceptance criteria for sensitivity and specificity in their guidelines and rules for validation schemes. Only NordVal (Anonymous 2005 b) has set a criterion for sensitivity in its protocol for the validation of alternative microbiological methods. Generally, sensitivity values above $95 \%$ are considered as acceptable. However, also NordVal does not mention a criterion for specificity.

As an example, the Salmonella results of the National Monitoring and Control Programme for Salmonella and Campylobacter in the Netherlands, which has been implemented by the Dutch Product Boards for Livestock, Meat and Eggs (PVE), are taken. In the period of 2002-2005, the percentages of contaminated breast skin and fresh breast meat were $9 \%$ and 3\%, respectively (Van der Fels-Klerx et al. 2008). With a sensitivity and specificity of $95 \%$, from every 1,000 batches tested on breast skins, five batches will be wrongly destined for fresh poultry and 46 batches will be wrongly decreased in value. When testing breast meat, these numbers would be two and 49, respectively. With a sensitivity and specificity of $99 \%$, from every 1,000 batches tested on breast skins, one batch will be wrongly destined for fresh poultry and nine batches will be wrongly decreased in value. When testing breast meat, these numbers will be zero and ten, respectively. To make absolutely sure that no contaminated fresh poultry meat will be brought on the market for human consumption, sensitivity and specificity should be at least $99 \%$ or more.
However, such high requirements for sensitivity and specificity are probably unrealistic. Most of the commercial tests kits available do not reach these high levels (see Table 4), and it can be argued whether these high levels will ever be feasible for (rapid) tests for the detection of Salmonella.

\section{Suggested Sampling Plan Approaches for Poultry Meat}

The required number of samples that needs to be analyzed per unit of time depends on the sampling plan that will be prescribed in future European legislation. In the National Monitoring and Control Programme for Salmonella and Campylobacter in The Netherlands, 30 cecum samples are taken from each broiler house and pooled to one mixed sample to check the Salmonella status upon arrival at the slaughterhouse. For monitoring the Salmonella status at departure from the slaughterhouse, one sample of breast skin is taken from each flock (one or more broiler houses from the same farmer, delivered on the same day) and one sample of breast meat is taken each day (Van der Fels-Klerx et al. 2008; Anonymous 2002a, b).

The required number of samples to detect at least one truly positive sample in a lot can be calculated with Eq. 6:

$n \geq \frac{\log (1-C)}{\log (\operatorname{Sp}(1-\mathrm{TP})+(1-\mathrm{Se}) \mathrm{TP})}$

in which $n$ is the number of samples, $C$ is the required level of confidence, TP is the within-lot prevalence, $\mathrm{Sp}$ is the specificity, and Se the sensitivity of the test (Christensen and Gardner 2000).

In Table 2, the required number of samples is given for a confidence level of $95 \%$ for a within-lot prevalence ranging from $1 \%$ to $90 \%$ and a sensitivity and specificity of 99\%. Exact figures about within-flock prevalence for Salmonella are hardly available. In a report of Nauta (1998), an average prevalence of $10 \%$ is estimated, while in a report of Rasschaert (2007), figures from lower than $5 \%$ to over $70 \%$ are mentioned. With a $5 \%$ within-flock prevalence, about 60 individual samples should be tested negative to claim with a confidence level of $95 \%$ that the flock is Salmonella-negative.

Pooling of samples has the advantage over an individual test that more individuals can be represented in a pooled test for the same fixed laboratory costs. Disadvantages of pooled testing are logistical restraints associated with

Table 2 Required number of samples at a confidence level of $95 \%$ and a sensitivity and specificity of $99 \%$ at different within-lot prevalences

\begin{tabular}{|c|c|c|c|c|c|c|c|c|c|c|c|}
\hline & \multicolumn{11}{|c|}{ Within lot prevalence $(\%)$} \\
\hline & 1 & 5 & 10 & 20 & 30 & 40 & 50 & 60 & 70 & 80 & 90 \\
\hline Required number of samples & 301 & 59 & 29 & 14 & 9 & 6 & 4 & 3 & 3 & 2 & 1 \\
\hline
\end{tabular}


processing of larger sample weights or volumes in the laboratory and a potential decrease in sensitivity compared with individual testing due to, for example, effects of dilution (Christensen and Gardner 2000). When a pool is qualified positive as one or more samples in the pool are positive and the lot is qualified positive as one or more pools are positive, the level of confidence for detecting a contaminated lot can be calculated with Eq. 7:

$$
C=1-\left[1-(1-\mathrm{TP})^{k} \times(1-\mathrm{Pse})+(1-\mathrm{TP})^{k} \times \mathrm{Psp}\right]^{r}
$$

in which $C$ is the level of confidence based on pool testing, TP is the within-lot prevalence, Psp is the specificity and Pse is the sensitivity of the test for pool testing, $k$ is the number of samples per pool, and $r$ is the number of pools (Christensen and Gardner 2000). In the case that sensitivity and specificity would be the same for individual testing as for pool testing, two pools of 30 samples should be tested negative to claim with $95 \%$ confidence that a lot is negative in the example above. However, it is likely that Pse will be lower than Se, especially when TP is low and the pool size is large. Conversely, Psp should exceed Sp because dilution should make it less likely to have a false-positive pool test result than a false-positive individual test result (Anonymous 2006b). Little information is available about pool sensitivities and specificities in relation to individual test sensitivities and specificities. Van de Giessen et al. (1991) tested three methods for detection of Salmonella in fecal samples of 27 poultry flocks: (a) individual tests of 20 samples per flock, (b) 20 fecal samples mixed in two pool samples per flock, and (c) individual preenrichment, followed by mixing of the obtained cultures in two wetpool samples per flock. The samples were analyzed according to the ISO/DIS 6579 method. Their results showed that 26 samples with method a (96\%), 23 samples with method b (85\%), and 25 samples with method c (92\%) out of the 27 tested flocks were tested positive for Salmonella. When it is assumed in the example above that by pooling sensitivity is decreased to $90 \%$ and specificity is increased to $100 \%$, three pools of about 25 samples tested negative are required to claim with $95 \%$ confidence that the flock is negative. For a better determination of the required number of samples, more research should be done to the actual within-lot prevalence of Salmonella and to the sensitivities and specificities of pool testing.

\section{Operational Requirements}

The consequence of the requirement with respect to time of analysis (result available within hours with a maximum of 1 day) is that the analyses should be carried out on site of the slaughterhouse. Most slaughterhouses do not have a laboratory on site or have a laboratory for routinely methods only. It is not common practice for slaughterhouses to test for pathogens on site because this necessitates holding cultures of pathogens and having specialized facilities for handling infectious bacteria. In addition, the educational level of the employees is relatively low. Therefore, the rapid detection method should be commercially available, preferably in the form of ready-to-use test kits, without extra enrichment steps.

\section{Costs}

In general purchasing, operational costs and maintenance costs of the rapid detection method should be as low as possible. However, Swanenburg et al. showed that the costs of a monitoring system to prevent Salmonella-contaminated flocks destined for human consumption are mainly caused by the decrease in value of Salmonella-contaminated flocks. The monitoring costs are just a fraction of the total costs (Swanenburg et al. 2005). False-negative test results can result in costly recalls and costs associated with litigation and also the costs of waiting in order to deliver products will have a much bigger impact (Evers 2004). Therefore, it is more important to have a reliable test method that will deliver results in time than a low-cost method. The costs of the method and equipment, logistics, human resources utilization, and general management involved will not be discussed further in this paper.

In Table 3, a summary is given of the postulated parameters and accompanying requirements.

Table 3 Overview of requirements with respect to rapid detection methods for Salmonella

\begin{tabular}{|c|c|}
\hline Parameter & Requirement \\
\hline Detection limit & $\begin{array}{l}\text { Ability to detect a single Salmonella } \\
\text { bacterium in } 25 \mathrm{~g}\end{array}$ \\
\hline Time of analysis & $\begin{array}{l}\text { Preferably within hours with an absolute } \\
\text { maximum of } 1 \text { day }\end{array}$ \\
\hline Validation & $\begin{array}{l}\text { The detection method should be validated } \\
\text { against standard tests and evaluated by } \\
\text { collaborative studies. Preference should be } \\
\text { given to naturally contaminated samples }\end{array}$ \\
\hline Sensitivity & Preferably at least $99 \%$ \\
\hline Specificity & Preferably at least $99 \%$ \\
\hline Capacity & $\begin{array}{l}3 \text { pooled samples per batch of } 25 \\
\text { individual samples each }\end{array}$ \\
\hline Operation & $\begin{array}{l}\text { User-friendly - easy to operate for employees } \\
\text { in a slaughterhouse who do not have a } \\
\text { laboratory education. No skill required } \\
\text { to use the method, commercially available }\end{array}$ \\
\hline
\end{tabular}




\section{Rapid Detection Methods for Salmonella}

There are several rapid and automated microbiological techniques available to food processors for the identification and detection of Salmonella in food products. Methods widely used include the following categories: modified conventional methods, immunological methods, nucleic acid-based methods, and diagnostic biosensors. These categories will be discusses in more detail below.

\section{Modified Conventional Methods}

Modified conventional methods include chromogenic or fluorogenic substrates in selective media. Using these selective media, detection, enumeration, and identification can be performed directly on the isolation plate, thus eliminating the use of subculture media and further biochemical tests (Tacken and van Horne 2006). In general, these selective media provide test results 1 day earlier, compared with conventional methods, but they are not fast enough for the purpose of steering the destination of a finished product in a slaughterhouse. Therefore, these methods will not be discussed in further detail.

\section{Immunoassays}

Immunological methods are based on the specific binding reaction that occurs between an antibody and the antigen to which it is directed (Betts 2002). The selection of the appropriate antibodies allows the construction of tests with broad to narrow selectivity. Only a few basic forms of antibody assay formats exist, but many different modifications are commercially available. The different assay formats include: latex agglutination tests, immunodiffusion test format, enzyme-linked immunoabsorbent assay (ELISA), and immunochromatography (von BlankenfeldEnkvist and Brännback 2002). In latex agglutination tests, latex beads are coated with antibodies that agglutinate specific antigens and form a visible precipitate (De Boer and Beumer 1999). Latex agglutination kits have tended to be used for the confirmation of microbiological identity, rather than for the detection of the target organisms (Betts 2002). In immunodiffusion tests, an enrichment sample is placed in a gel matrix with the antibody. If the antigen is present, a visible line of precipitation is found (von Blankenfeld-Enkvist and Brännback 2002). ELISA exists in different formats, but usually consists of a sandwich procedure. The antibody is bound to a solid matrix. The sample is added, and upon presence of the antigen, binding occurs that can be monitored using a secondary antibody coupled to an enzyme. Upon adding of substrate, a color reaction occurs (von Blankenfeld-Enkvist and Brännback 2002). Immunochromatography is also a sandwich proce- dure, but the secondary antibody is coupled to latex beads or colloidal gold. The enriched sample is transported through a series of chambers and no washing is necessary (von Blankenfeld-Enkvist and Brännback 2002). Immunomagnetic separation (IMS) techniques can be used to replace or supplement and speed up the enrichment step that is usually necessary before the detection of pathogens. IMS differs from the assay format described above as it is not a detection method in itself. It can be combined with different end-detection methods. For IMS, paramagnetic beads coated with various antibodies are used to concentrate target bacteria selectively. The sample is mixed with the beads, and after incubation, the bead-bacteria complex is extracted through the application of a magnetic field with a magnetic device (von Blankenfeld-Enkvist and Brännback 2002).

\section{Nucleic Acid-Based Detection Methods}

The basis of any nucleic acid-based detection (NAD) assay is a specific nucleic acid target sequence, unique to the bacterial pathogen of interest (Glynn et al. 2006). Two basic techniques are applied for the detection and identification of microorganisms: (1) direct hybridization and (2) in vitro amplification (Scheu et al. 1998). Nucleic acid hybridization is typically between a DNA or RNA molecule present in the target organism and a probe DNA which has a sequence complementary to the target sequence. The first step in these genetic methods is usually lysis of the cells and often followed by purification of the released nucleic acid prior to hybridization to the labeled DNA probe. When the hybrid is formed, different detection techniques can be used (De Boer and Beumer 1999). In the beginning, radioactive compounds were used for detection; the second generation uses enzymatic reactions (Fung 2002). Although there are some other advantages, such as rapidity and the possibility for automation, DNA-based methods which include an amplification step have become increasingly popular mainly due to their higher sensitivity. The most popular method of amplification is the polymerase chain reaction (PCR) technique. In this method, double-stranded DNA is first denatured into single strands and specific short DNA fragments (primers) are annealed to these DNA strands, followed by extension of the primers complementary to the single-stranded DNA with a thermostable DNA polymerase. This cycle is repeated several times and leads to an exponential increase of the numbers of copies of the target DNA. For detection of the amplification products, either gel-based (size-dependent) systems or real-time PCR (sequence-dependent) is used (Scheu et al. 1998). Nucleic acid sequence-based amplification (NASBA) is an RNAbased amplification technology that is suitable for amplification of pathogen-specific RNA targets and for applications where the assessment of the viability status of a pathogen is a 
requirement (Glynn et al. 2006). An emerging technology based on NAD is DNA microarrays. DNA microarrays consists of a large number of probes (either oligonucleotides or cDNAs) immobilized on a solid surface such as specially treated glass. Hybridizations are performed by application of labeled nucleic acid target in a liquid state to the microarray surface. Following appropriate hybridization and washing step, target nucleic acid bound to probes on the array surface are visualized using a microarray scanner (Glynn et al. 2006). The successful application of microarray analysis has been described for the detection of antibiotic resistance genes (Van Hoek et al. 2005; Van Hoek and Aarts 2008) and also for the detection of genes belonging to a broader group of markers representing flagellar and somatic antigen genes, virulence genes, phage-associated genes, and antibiotic resistance determinants (Malorny et al. 2007).

\section{Diagnostic Biosensors}

In general, three different assay formats are used in biosensors - the direct and the indirect format, the latter one either as a competitive or noncompetitive assay. In the case of the direct assay, the analyte is bound by its biorecognition element, which is detected directly. This can be an antigen binding to its antibody, a hormone binding to a receptor, or a substrate reacting with its enzyme and producing a product. The detection of these binding events is limited to the event itself and can be changed in mass, refractive index, impedance, $\mathrm{pH}$, etc. In contrast, in the indirect format, an additional reaction has to occur in order to detect the binding of analyte and biorecognition element. This additional reaction can either be competitive or noncompetitive. In both cases, a label is typically used for subsequent detection and quantification. The detection scheme is much less limited than in the case of the direct approach and depends on the nature of the label. This label can be optical, electrochemical, or massrelated and thus permits the use of any transduction principle with indirect assay formats in contrast to the constraints given by the direct assay, which is limited by the nature of the analyte itself (Baeumner 2003).

\section{Suitable Detection Methods for Testing of Salmonella in Poultry Slaughterhouses}

A selection of commercially available rapid detection methods for testing of Salmonella in poultry meat is given in Table 4 . This selection is based on the available information with respect to the requirements formulated in the "Requirements for Rapid Methods for Detection of Salmonella" section and the availability of ready-to-use test kits. Detection methods like Nuclisens ${ }^{\circledR}$ (NASBA-ECL assay), Biacore (biosensor), and microarrays are not considered in this overview because, for these tests, only basic test kits are provided where after the user should build his own assay with primers and probes. These methods could be suitable for a research laboratory, but are too complicated to use in a routine laboratory in a slaughterhouse.

Several methods are able to fulfill the requirement of detecting a single Salmonella bacterium in $25 \mathrm{~g}$. However, to obtain this detection limit all currently commercially available test methods need an enrichment step, which takes at least 6 up to $58 \mathrm{~h}$.

The number of detection methods, which are able to give results within $24 \mathrm{~h}$, is limited. The most promising methods are Reveal ${ }^{\circledR}$ System from Neogen, Salmonella UNIQUETM from TECRA ${ }^{\circledR}$, MAGDA $^{\mathrm{TM}}$ Salmonella from Raisio Diagnostics, and TaqMan ${ }^{\circledR}$ from Applied Biosystems. The results of these tests will be available the next day (negative or presumptively positive results). Also, the iQ-Check ${ }^{\mathrm{TM}}$ from Bio-Rad Laboratories is able to give results the next day, but, for detecting 1-5 cfu/g, an extra enrichment step of $21 \mathrm{~h}$ is needed. The positive results of the Reveal ${ }^{\mathbb{B}}$ System, Salmonella UNIQUETM, MAGDA ${ }^{\mathrm{TM}}$ Salmonella, and $\mathrm{iQ}-\mathrm{Check}^{\mathrm{TM}}$ have to be confirmed with cultural methods, followed by biochemical identification. This confirmation will take at least an additional $24 \mathrm{~h}$. However, a slaughterhouse may choose to steer the suspicious flocks into the direction of industrial treatment, rather than to wait for the confirmation. This will imply a potential negative financial impact in the case of false-positive test results, but the costs of waiting for the confirmation might be higher.

All selected test were certified by one or more of the validation bodies AOAC, AFNOR, NordVal, or MicroVal, except for Transia ${ }^{\circledR}$ Card Salmonella, Magda ${ }^{\mathrm{TM}}$ Salmonel$l a$, and TaqMan ${ }^{\circledR}$ Salmonella enterica. According to the representative of Applied Biosystems, the AOAC and AFNOR validation for TaqMan ${ }^{\circledR}$ Salmonella enterica is expected this year.

Information with respect to sensitivity and specificity available in literature and on websites of suppliers of rapid detection methods is limited and is sometimes incomplete. In addition, the information is difficult to compare due to the fact that different methods are used to determine these characteristics. In some tests, naturally contaminated samples are used, whereas in other tests artificially contaminated samples or pure cultures are used. Sometimes, sensitivity and specificity are determined in relation to the true Salmonella contamination; in other cases, they are related to the used reference method. It is not always clear whether the presented figures for sensitivity and specificity include or exclude confirmation tests. For the purpose of testing poultry meat in slaughterhouses to steer the logistic process, preferably the sensitivity and specific- 


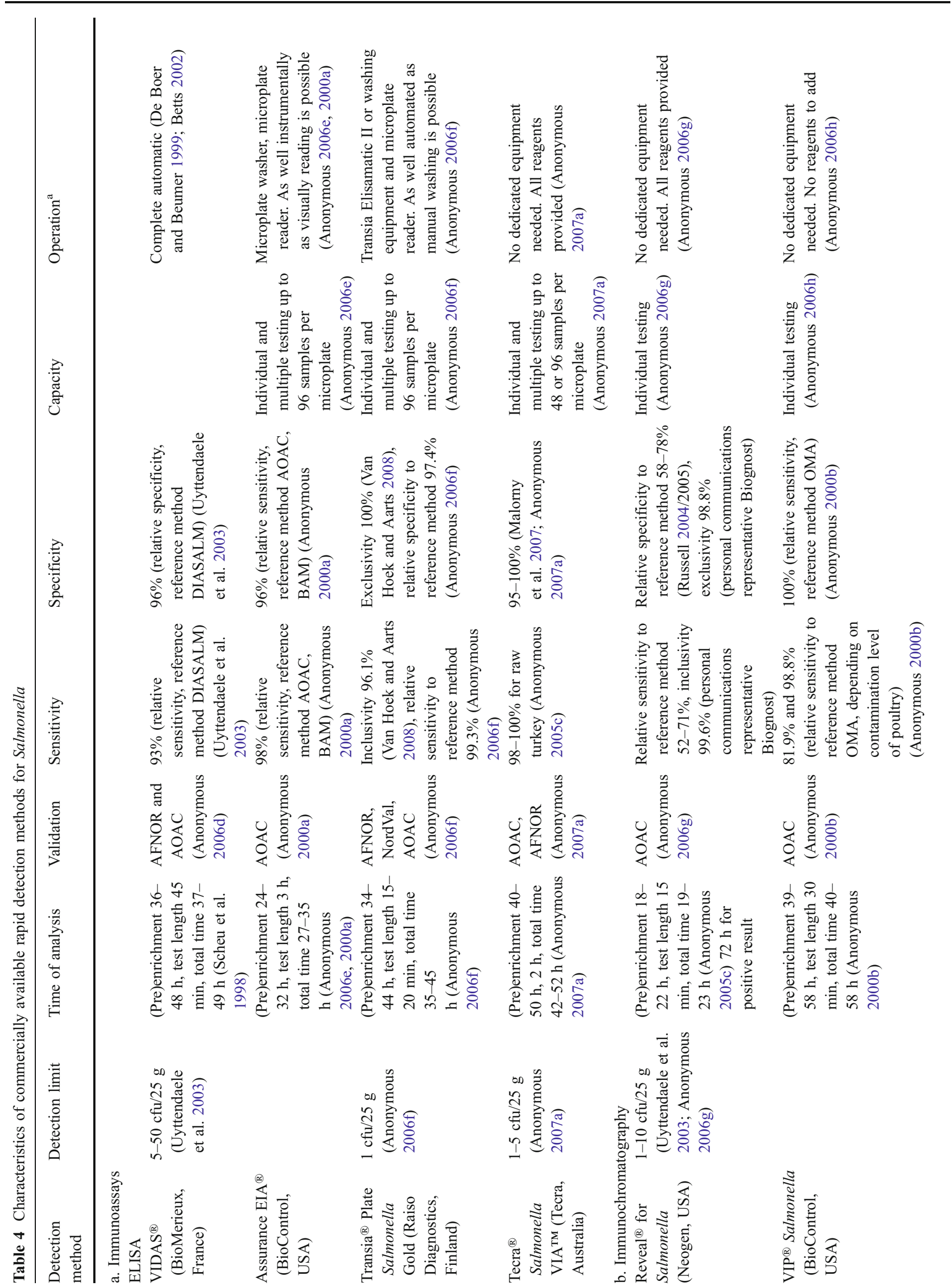



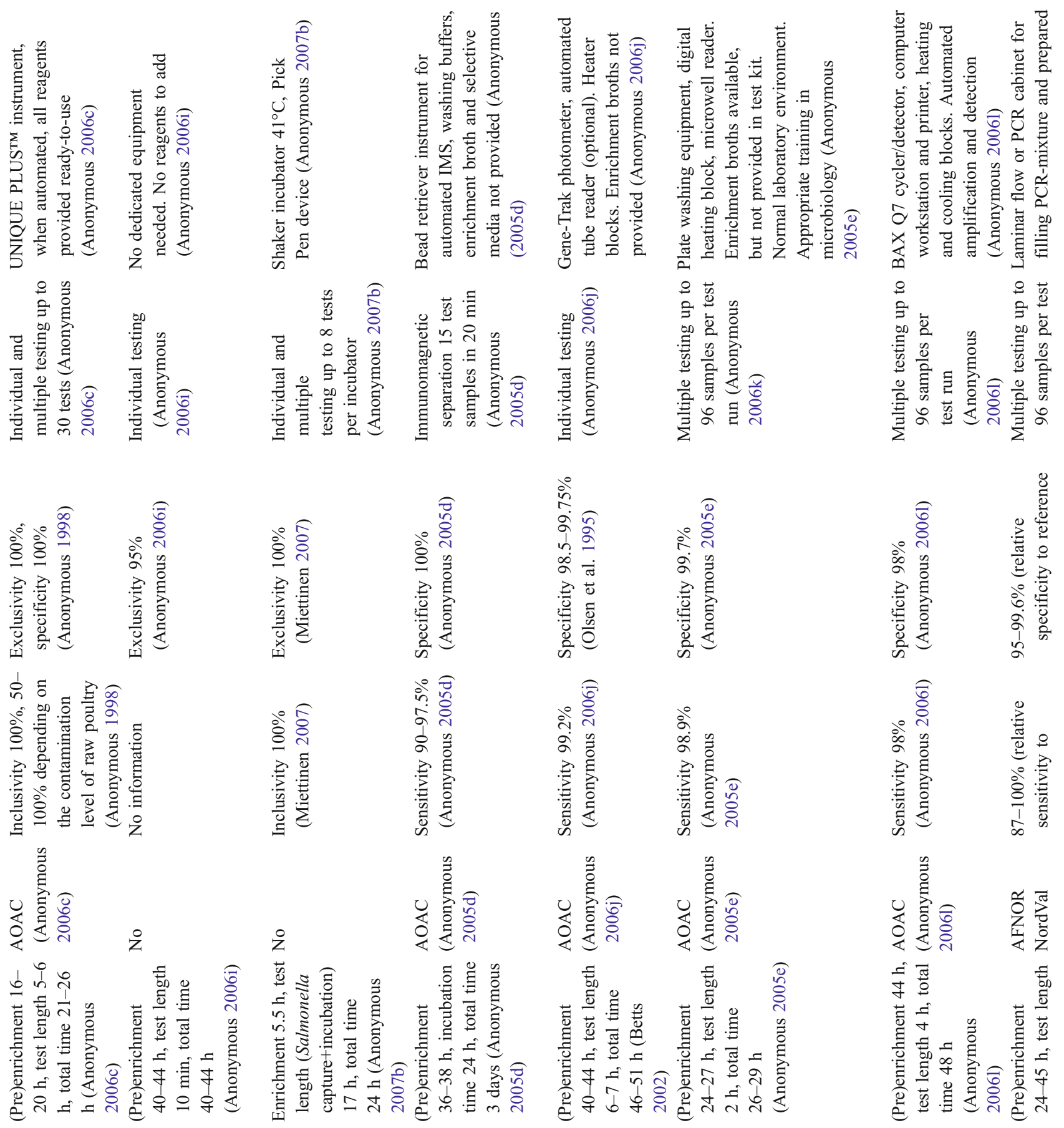

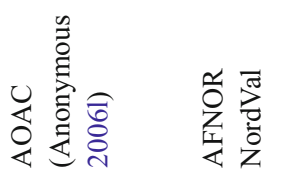

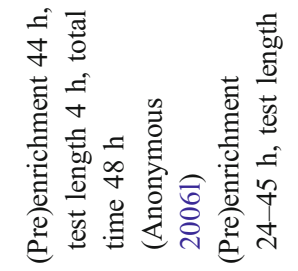

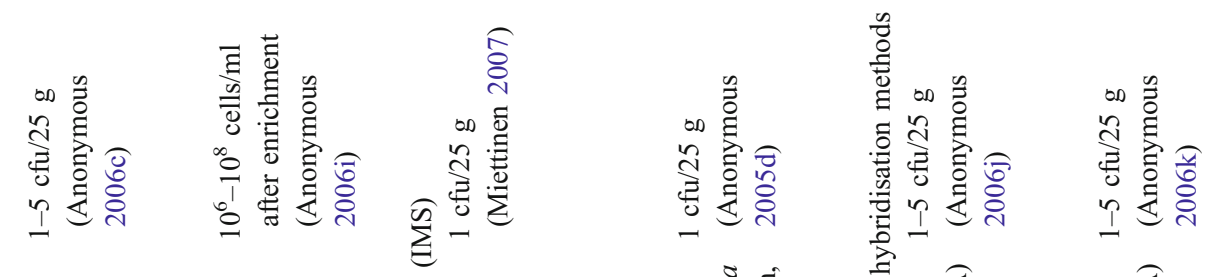

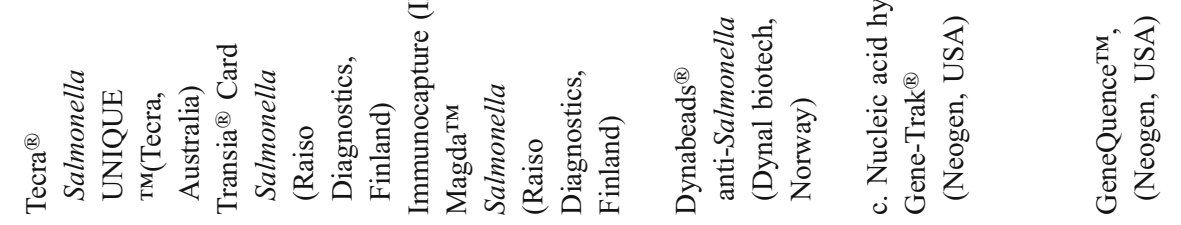

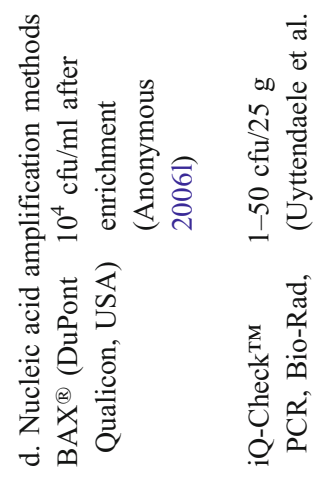




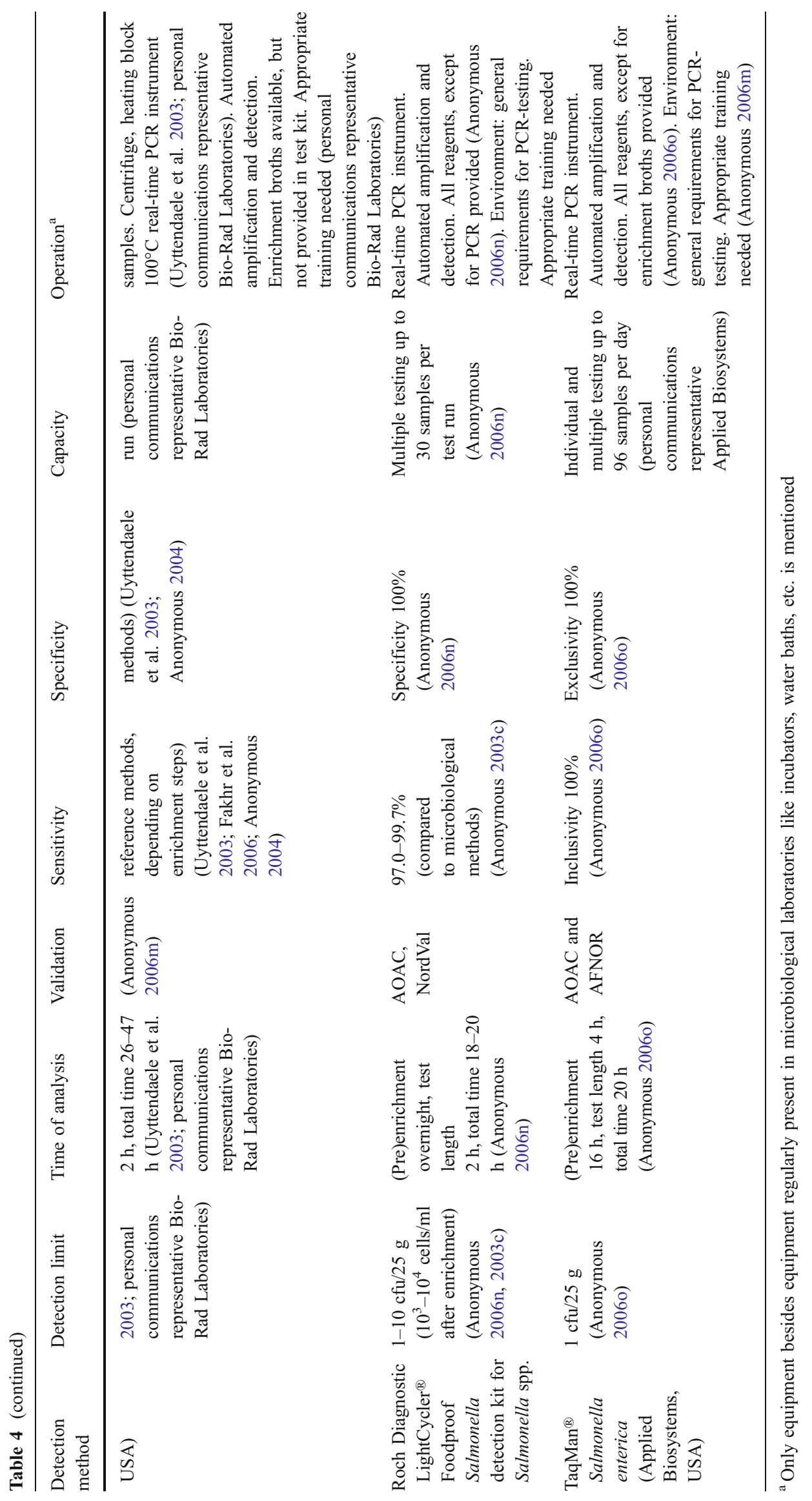


ity of the detection methods should be known excluding the confirmation test because of the length of the confirmation test. For the following tests, sensitivity and/or specificity percentages of at least $99 \%$ are given in literature or claimed by the supplier: Transia ${ }^{\circledR}$ Plate Salmonella Gold test, Tecra ${ }^{\circledR}$ Salmonella VIA, VIP ${ }^{\circledR}$-system, Tecra UNIQUETM, Gene-Trak ${ }^{\circledR}$, GeneQuence ${ }^{\mathrm{TM}}$, and $\mathrm{iQ}$ Check $^{\mathrm{TM}}$. The Reveal ${ }^{\circledR}$ system, MAGDA ${ }^{\mathrm{TM}}$ Salmonella test, and Taqman ${ }^{\circledR}$ claim inclusivity and/or exclusivity rates (pure cultures) of at least 99\%.

Tests like the Reveal ${ }^{\circledR}$ system, the VIP ${ }^{\circledR}$-system, TECRA $^{\circledR}$ Salmonella UNIQUETM ${ }^{\mathrm{T}}$, and the Transia ${ }^{\circledR}$ Card Salmonella are intended to be applied as an individual test. With these tests, the capacity depends on the capacity of incubators for (pre)enrichment and operators. Other tests like $\operatorname{VIDAS}^{\circledR}$, Assurance EIA $^{\circledR}$, Transia ${ }^{\circledR}$ Plate, Tecra ${ }^{\circledR}$ Salmonella VIA, GeneQuence ${ }^{\mathrm{TM}}, \mathrm{BAX}^{\circledR}$, iQ-Check ${ }^{\mathrm{TM}}$, and TaqMan ${ }^{\circledR}$ use 48- or 96-well microplates. The advantage of the individual test is a higher flexibility; a test can be started on every moment of the day, which may be important with respect to timely dispatch of the products. However, when a slaughterhouse slaughters a lot of flocks, microplate systems offer the advantage of testing many samples simultaneously, which in the end could be favorable. All selected tests are fit for use with respect to the suggested sampling plan of three pooled samples per batch.

All current rapid detection methods need an enrichment step to obtain the detection limit of $1 \mathrm{cfu} / 25 \mathrm{~g}$ of sample. Regular equipment for a microbiological laboratory like incubators (sometimes several in case of incubation at more than one temperature), weighing, mixing, and pipetting are, therefore, necessary for all methods. For the Salmonella VIA $^{\mathrm{TM}}$ test, the Reveal ${ }^{\circledR}$ test, the $\mathrm{VIP}^{\circledR}{ }^{\circledR}$-system, and the Transia ${ }^{\circledR}$ Card Salmonella, no further equipment is necessary and all reagents, except for the enrichment broths, are provided in ready-to-use test kits. The same applies to the Salmonella UNIQUETM test; however, for this system, it is also possible to automate the test by using the UNIQUE PLUS ${ }^{\text {TM }}$ Instrument (Anonymous 2006c). All other methods require dedicated equipment. Basic microbiological laboratory knowledge and experience is necessary for all selected methods. The most commercially available test methods are easy to use because all necessary reagents, except for enrichment broths, are provided in the test kits.

Taking into account all requirements, for four detection methods, it is claimed that $1 \mathrm{cfu}$ Salmonella/25 $\mathrm{g}$ of sample can be detected within $24 \mathrm{~h}$ (Reveal ${ }^{\circledR}$ System from Neogen, Salmonella UNIQUETM from TECRA ${ }^{\circledR}$, MAGDA $^{\mathrm{TM}}$ Salmonella from Raisio Diagnostics, and TaqMan ${ }^{\circledR}$ from Applied Biosystems). For all four tests, inclusivity (the ability of the method to detect the target analyte from a wide range of strains) and exclusivity (the lack of interference from a relevant range of nontarget strains of the test method) figures are presented (100\%), only for Salmonella UNIQUETM from TECRA ${ }^{\circledR}$ sensitivity $(50$ $100 \%$, depending on contamination level) and specificity $(100 \%)$ figures are also presented. The MAGDA ${ }^{\mathrm{TM}}$ Salmonella and TaqMan ${ }^{\circledR}$ are not yet certified by an official validation body.

\section{Conclusions and Recommendations}

A large number of commercial rapid test are available for the detection of Salmonella in poultry meat. For the purpose of using test results to steer the finished product into the direction of fresh poultry meat or industrial treatment, the most important requirements to the detection methods are the detection limit ( $1 \mathrm{cfu} / 25 \mathrm{~g})$, the time of analysis (within hours up to a maximum of $24 \mathrm{~h}$ ), and the sensitivity and specificity (both preferably $>0.99$ ). None of the selected methods satisfy all these requirements. Four tests are able to deliver results within $24 \mathrm{~h}$; for three of them, suspect test results have to be confirmed with conventional tests to prevent false-positive results. For only one of the four tests, figures for sensitivity and specificity are available; the other suppliers provide only figures about inclusivity and exclusivity. Two of the tests are not yet certified by an official validation body.

Faster detection methods for detecting Salmonella in poultry meat should be developed to make it possible to steer the finished products of the slaughterhouse into the direction of fresh poultry for the retail market or into the direction of industrial treatment.

Information about sensitivity and specificity is very diverse and not very well comparable due to different validation methods and different ways of presenting results. It is recommended to set up a study to investigate the sensitivity and specificity of the tests, specifically for naturally contaminated poultry meat under the same test conditions. In such a study, the sensitivity and specificity of individual tests should also be compared to those of pooled tests. It is also recommended that more research is done to the actual within-lot prevalence of Salmonella in finished products for a better determination of the required number of samples. When Salmonella reduction is successful, the reducing within-lot prevalence will require a reliable pooled testing, otherwise the number of required samples will be too large to handle.

Acknowledgments The research described in this paper was performed within the strategic research programme of the Dutch Ministry for Agriculture, Nature and Food Quality. The authors kindly thank the contribution of the representatives of the suppliers of the detection methods reviewed as well as Irene Pol-Hofstad and Wilma Jacobs-Reitsma of RIKILT - Institute of Food Safety. 
Open Access This article is distributed under the terms of the Creative Commons Attribution Noncommercial License which permits any noncommercial use, distribution, and reproduction in any medium, provided the original author(s) and source are credited.

\section{References}

Anonymous (1998) Certificate of performance tested methods, certificate no. 971001, Tecra Uniqueä Salmonella, AOAC Research Institute

Anonymous (1999) AOAC international qualitative and quantitative microbiology guidelines for methods validation, microbiology guidelines. J AOAC Int 82:402-416

Anonymous (2000a) AOAC official method 992.11, motile and nonmotile Salmonella in foods. AOAC International

Anonymous (2000b) AOAC official method 999.09, VIP for Salmonella for the detection of motile and nonmotile Salmonella in all foods. AOAC International

Anonymous (2002a) Besluit Blindedarmmonstername 1999, Integrale tekst bijgewerkt t/m wijziging 2002-I, Productschap Pluimvee en Eieren (in Dutch)

Anonymous (2002b) Besluit Eindproductencontrole 1999, Integrale tekst bijgewerkt t/m wijziging 2002-III, Productschap Pluimvee en Eieren (in Dutch)

Anonymous (2003a) Regulation (EC) No 2160/2003 of the European Parliament and of the Council of 17 November 2003 on the control of Salmonella and other specified food-borne zoonotic agents, European Union. Off J Eur Union L 325:1-15

Anonymous (2003b) NEN-EN-ISO (International Organization for Standardization) 16140. Microbiology of food and animal feeding stuffs - protocol for the validation of alternative methods

Anonymous (2003c) Certification report AOAC Research Institute Performance testes Method SM 120301. Roche Diagnostics LightCyclerÒ foodproof Salmonella spp. in combination with ShortPrep foodproof $1 \mathrm{Kit}$

Anonymous (2004) Validation certificate for alternative method analysis according to the EN ISO 16 40:2003 standard, Certificate BRD-07/6-07/04, iQ-Check Salmonella, validation date 01.07.2004, AFNOR Certification

Anonymous (2005a) Regulation (EC) No 2073/2005 of 15 November 2005 on microbiological criteria for foodstuffs, European Union. Off J Eur Union L 338:1-26

Anonymous (2005b) Protocol for the validation of alternative microbiological methods, NordVal validation. Available at http://www.nmkl.org/NordVal/ValD-2005-01-01.doc

Anonymous (2005c) AOAC Official method 998.09, Salmonella in Foods, AOAC International

Anonymous (2005d) Product information on dynabeadsÒ antiSalmonella, Dynal Biotech. Available at http://www.dynal.no

Anonymous (2005e) Technical product information, GeneQuenceä Salmonella assay 24-hour enrichment procedure, Neogen

Anonymous (2006a) The community summary report on trends and sources of zoonoses, zoonotic agents, antimicrobial resistance and foodborne outbreaks in the European Union in 2005. The EFSA Journal 2006(94):2-288. Available at: http://www.efsa.europa.eu/ EFSA/DocumentSet/Zoonoses_Report_EU_ en_2005,3.pdf

Anonymous (2006b) MicroVal Rules and certification scheme, version 5, MicroVal Secretariat NEN

Anonymous (2006c) Product information on TECRA Salmonella UNIQUE ä, Tecra. Available at http://www.tecra.net

Anonymous (2006d) Product information on VIDASÒ Safety, BioMérieux. Available at http://www.biomerieux.com

Anonymous (2006e) Product information on Assurance Gold EIA, Bioconctrol. Available at http://www.bioconctrolsys.com
Anonymous (2006f) Product information on Transia Plate Salmonella Gold, Raisio Diagnostics. Available at http://www.diffchamp. com

Anonymous (2006g) Product information for the RevealÒ for Salmonella, Neogen. Available at http://www.neogen.com

Anonymous (2006h) Product information on VIPÒ, Bioconctrol. Available at http://www.bioconctrolsys.com

Anonymous (2006i), Product information on Transia Card Salmonella, Raisio Diagnostics. Available at http://www.diffchamp.com

Anonymous (2006j) Product information for the GENE-TRAKOे Salmonella assay, Neogen. Available at http://www.neogen.com

Anonymous (2006k) GeneQuence, Automated system for pathogen detection, Neogen. Available at http://www.neogen.com

Anonymous (20061) Product information on BAXÒ System PCR Assay, DuPont Qualicon. Available at http://www.dupont.com

Anonymous (2006m) Product information on iQ-Check Salmonella kit, Bio-Rad. Available at http://www.bio-rad.com

Anonymous (2006n) Product information of LightCyclerÒ foodproof Salmonella Detection Kit, Roche Diagnostics. Available at http:// www.roche-applied-science.com

Anonymous (20060) Product information on TaqManÒ Salmonella enterica detection kit, Applied Biosystems. Available at http:// www.appliedbiosystems.com

Anonymous (2007a) Product information on TECRA Salmonella VIAä, Tecra. Available at http://www.tecra.net

Anonymous (2007b) Product information on Magdaä Salmonella, Raisio Diagnostics. Available at http://www.raisiodiagnostics. com

Baeumner AJ (2003) Biosensors for environmental pollutants and food contaminants. Anal Bioanal Chem 377:434-445 doi:10.1007/s00216-003-2158-9

Betts R (2002) Detecting pathogens in food. In: Blackburn C de W, McClure PJ (eds) Foodborn pathogens, hazard, risk analysis and control. Cambridge, Woodhead, pp 13-52

Christensen J, Gardner IA (2000) Herd-level interpretation of test results for epidemiologic studies of animal diseases. Prev Vet Med 45:83-106 doi:10.1016/S0167-5877(00)00118-5

De Boer E, Beumer R (1999) Methodology for detection and typing of food-borne micro-organisms. Int J Food Microbiol 50:119-130 doi:10.1016/S0168-1605(99)00081-1

Evers EG (2004) Predicted quantitative effect of logistic slaughter on microbial prevalence. Prev Vet Med 65:31-46 doi:10.1016/j. prevetmed.2004.06.008

Fakhr MK, McEvoy JM, Sherwood JS, Logue CM (2006) Adding a selective enrichment step to the iQ-Checkä real-time PCR improves the detection of Salmonella in naturally contaminated retail turkey meat products. Lett Appl Microbiol 43:78-83 doi:10.1111/j.1472-765X.2006.01903.x

Feldsine P, Abeyta C, Andrews WH (2002) AOAC International Methods Committee Guidelines for the validation of qualitative and quantitative food microbiological official methods of analysis. J AOAC Int 85:1187-1200

Fung DYC (2002) Rapid methods and automation in microbiology. Comprehensive Reviews in Food Science and Food Safety 1:3-14

Glynn B, Lahiff S, Wernecke M, Barry T, Smith TJ, Maher M (2006) Current and emerging molecular diagnostic technologies applicable to bacterial food safety. Int J Dairy Technol 59:126-139 doi:10.1111/j.1471-0307.2006.00253.x

Gunnarsson RK, Lanke J (2002) The predictive value of microbiologic diagnostic tests if asymptomatic carriers are present. Stat Med 21:1773-1785 doi:10.1002/sim.1119

Ivnitski D, Abdel-Hamid I, Atanasov P, Wilkins E, Stricker S (2000) Application of electrochemical biosensors for detection of food pathogenic bacteria. Electroanalysis 12:317-325 doi:10.1002/ (SICI)1521-4109(20000301)12:5<317::AID-ELAN317>3.0. $\mathrm{CO} ; 2-\mathrm{A}$ 
Löfstrom C, Axelson CE, Rådström P (2008) Validation of a diagnostic PCR method for routine analysis of Salmonella spp. in animal feed samples. Food Analytical Methods 1:23-27 doi:10.1007/s12161-007-9003-2

Malorny B, Hoorfar J, Bunge C, Helmuth R (2003) Multicenter validation of the analytical accuracy of Salmonella PCR: toward an international standard. Appl Environ Microbiol 69:290-296 doi:10.1128/AEM.69.1.290-296.2003

Malorny B, Bunge C, Guerra B, Prietz S, Helmuth R (2007) Molecular characterisation of Salmonella strains by an oligonucleotide multiprobe microarray. Mol Cell Probes 21:56-65 doi:10.1016/j.mcp.2006.08.005

Martin SW (1977) The evaluation of tests. Can J Comp Med 41:19-25

Meloen RH, Oonk HB, van de Wiel DFM et al (2001) Chaperonnes, deelproject 4 Rapportage Technology Scan, Wageningen, RIKILT-Wageningen UR, report 2001.007 (in Dutch)

Miettinen T (2007) Cutting sample preparation time in Salmonella testing. Available at http://www.scientistlive.com

Nauta MJ (1998) Modellering van de transmissie van Salmonella via pluimveevlees, van bedrijf tot consument: de stand van zaken, Bilthoven, RIVM, report 257851001 (in Dutch)

Olsen JE, Aabo S, Hill W et al (1995) Probes and polymerase chain reaction for detection of food-borne bacterial pathogens. Int J Food Microbiol 28:1-78 doi:10.1016/0168-1605(94) 00159-4

Peplow MO, Correa-Prisant M, Stebbins ME, Jones F, Davies P (1999) Sensitivity, specificity, and predictive values of three Salmonella rapid detection kits using fresh and frozen poultry environmental samples versus those of standard plating. Appl Environ Microbiol 65:1055-1060

Rasschaert G (2007) Molecular epidemiology of Salmonella and Campylobacter contamination of poultry during transport and slaughter. University Gent, Faculty Veterinary Medicine
Russell SM (2004/2005) Testing Salmonella and Campylobacter: a methods update. Food Safety magazine 10:28,30,32,77-80

Scheu PM, Berghof K, Stahl U (1998) Detection of pathogenic and spoilage micro-organisms in food with the polymerase chain reaction. Food Microbiol 15:13-31 doi:10.1006/fmic.1997.0134

Swanenburg M, Rijsman VMC, van Hoek AHAM et al (2005) Eindrapportage project "Ketengerichte monitoring en Surveillance in de pluimveevleesketen", Lelystad, Animal Science Group -Wageningen UR, report ASG05/100443 (in Dutch)

Tacken GML, van Horne PLM (2006) Handelsstromen van pluimveevlees (Trade in poultry meat), The Hague, LEI-Wageningen UR, report 5.06.03 (in Dutch)

Uyttendaele M, Vanwildemeersch K, Debevere J (2003) Evaluation of real-time PCR vs automated ELISA and a conventional culture method using a semi-solid medium for detection of Salmonella. Lett Appl Microbiol 37:386-391 doi:10.1046/j.1472-765X. 2003.01415.x

Van de Giessen AW, Peters R, Berkers PATA, Jansen WH, Notermans SHW (1991) Salmonella contamination of poultry flocks in the Netherlands. Vet Q 13:41-46

Van der Fels-Klerx HJ, Jacobs-Reitsma WF, van Brakel R, van de Voet H, van Asselt ED (2008) Prevalence of Salmonella in the broiler supply chain in the Netherlands. J Food Prot (in press)

Van Hoek AHAM, Aarts HJM (2008) Microarray-based detection of antibiotic resistance genes in salmonella. Food Analytical Methods 1:95-108 doi:10.1007/s12161-007-9012-1

Van Hoek AHAM, Scholtens IMJ, Cloeckaert A, Aarts HJM (2005) Detection of antibiotic resistance genes in different Salmonella serovars by oligonucleotide microarray analysis. J Microbiol Methods 62:13-23 doi:10.1016/j.mimet.2005.01.004

von Blankenfeld-Enkvist G, Brännback M (2002) Technology trends and needs in food diagnostics. TEKES, Technology Review 132, Helsinki 